\title{
Effectiveness of Pelvic Floor Exercises Along with Faradic Stimulation on Bladder Retention and Quality of Life in Post-operative Case of Cauda Equina Syndrome. Case Report
}

\author{
Shiwani Nitin Redij ${ }^{1 *}$, Apoorva Ambolkar ${ }^{\mathbf{1}}$ and Gaurish Kenkre ${ }^{2}$ \\ ${ }^{1}$ Neuro-physiotherapist (MPT), Rehab Team of India, Mumbai, India \\ ${ }^{2}$ Certified Bobath SA, Director and Head Instructor Rehab Team of India, Mumbai, \\ India \\ *Corresponding Author: Shiwani Nitin Redij, Neuro-physiotherapist (MPT),
} Rehab Team of India, Mumbai, India.

DOI: 10.31080/ASOR.2022.05.0428
Received: January 24, 2022

Published: February 21, 2022

(C) All rights are reserved by Shiwani Nitin Redij., et al.

\begin{abstract}
Study Design: Case study. drome (CES); hence we report our case followed till 1 year postoperatively. case of CES.

Keywords: Cauda Equina Syndrome (CES); Pelvic Floor; Physical Therapy
\end{abstract}

Purpose: There is very less literature available regarding physical therapy intervention in urinary retention after cauda equina syn-

Overview: This study investigates the effect of pelvic floor exercises with faradic stimulation on urinary retention in post operative

\section{Introduction}

Cauda equina neurological condition caused by compression of the cauda equina, mainly secondarily to massive prolapsed intervertebral disc. Approximately $45 \%$ of cases of Cauda equine syndrome (CES) are due to herniated lumbar disc. CES is a rare but devastating condition [1]. The presentation of CES can be acute or chronic but maximum of patients present with sever back pain and radiculopathy. About $62 \%$ of patients report a recent and/or old episode of trauma [2].

Symptoms of CES are low back pain, unilateral or bilateral sciatica, sensory loss of the saddle area, motor deficit and/or loss of reflexes of the lower limbs, micturition dysfunction, defecation complaints, and/or sexual dysfunction [1]. In CES with retention there is damage below the micturition reflex center which affects some or all of the nerves in this region, depending on the type of lesions [3]. If all nerve roots are affected, the condition of a contractile detrusor and sphincter occur. However incomplete lesions are most common in which patient may register filling of the bladder, but activation of the detrusor and/or sphincter is not possible [4].

Hence surgery is necessary to tackle these neurological signs and symptoms as without surgery CES may progress and symptoms become permanent. Research suggests that surgical decompression within 48 hours of the onset of symptoms is necessary for maximum improvement of clinical signs and symptoms [5].

But even after surgery the recovery is not immediate and occurs over the years, affecting patient's activities of daily living and quality of life, thus rehab is important during the process of recovery. Physiotherapy treatment such as pelvic floor exercises and electrotherapy can help the patient to overcome the symptoms and reduce the complications hence improving the quality of life.

There is very less literature available regarding physical therapy intervention in urinary retention after cauda equine syndrome. 
Effectiveness of Pelvic Floor Exercises Along with Faradic Stimulation on Bladder Retention and Quality of Life in Post-operative Case of Cauda Equina Syndrome. Case Report

Hence we report our case with CES due to lumbar intervertebral disc prolapsed followed till 1 year postoperatively including description of physical therapy examination, evaluation and intervention.

\section{Case Presentation}

Patient is 35 year old female with sedentary lifestyle. Her weight was $75 \mathrm{kgs}$ and height $170 \mathrm{~cm}$ with BMI of $26 \mathrm{~kg} / \mathrm{m}^{2}$. In the month of May 2019 patient had experienced low back pain due to heavy lifting. Back pain was gradually followed by tingling and numbness in both lower extremities along with paresthesias in genitals. These symptoms persisted for almost one and half month. Pt had never experienced muscular weakness in lower limbs. During this period patient underwent conservative treatment. Patient was given diclofenac and gabapin NT medicine which relived only tingling and numbness in lower extremities but back pain and paresthesias in genitals persisted. Patient was able to perform normal daily activities and was getting normal urge to urinate and defecate.

But On $4^{\text {th }}$ June at night patient started experiencing burning sensations in bilateral inner thighs and on 5th June 2019, from the afternoon patient was not able to pass urine whole day and thus was taken to hospital. She was immediately taken to orthopaedic surgeon and her lumbosacral MRI was done which revealed diffuse posterior bulge with large broad-based central herniation with slight inferior migration of L5/S1 disc compressing thecal sac right budding $\mathrm{S} 1$ and intrathecal nerve roots with severe canal narrowing. Thus, patient underwent urgent partial discectomy at L5-S1 level on 6th June 2019. Post-surgery, bowel-bladder retention persisted without any back pain.

For two months patient was on Foley's catheter and later was accustomed to self-catheterization. Patient was performing intermittent catheterization 5 times a day and her residual volume was between $500-700 \mathrm{ml}$. patient was manually evacuating bowel. Also, patient experienced amenorrhea for 2-3 months followed by irregular menstrual cycle. Patient underwent physical therapy after surgery which was solely focused on lower limb muscle strengthening as well as back and abdominal strengthening in supine.

Patient was referred for physiotherapy by her family physician and thus, patient visited our physiotherapy clinic with the complaints of urinary and fecal retention on $2^{\text {nd }}$ January, 2019 since surgery i.e. $6^{\text {th }}$ June 2019.

\section{Examination}

Patient was examined by the physiotherapist in the clinic. Her examination revealed poor peri urethral sensations, lax anal sphincter. Pelvic floor assessment was done by using PERFECT scoring.

PERFECT scoring includes Power, Endurance, Repetition, Fast contraction and every contraction timed. Power is assessed by Modified Oxford grading of pelvic floor muscle strength. Test-retest reliability is 0.92 [6].

Urodynamic test reports revealed large bladder capacity with delayed proprioception and normal compliance with no evidence of any voluntary or involuntary detrusor activity. Ultrasonography report showed Residual volume of $620 \mathrm{ml}$. The SF36 questionnaire was used to determine the effect of urinary retention on her quality of life, the percentage of quality of life was $36.11 \%$.

Patient's vitals were stable and patient was made aware about the internal vaginal examination. Patient was mentally competent and provided consent for the examination. She was made comfortable prior examination and the procedure was briefly explained again. Therapists followed the infection control procedure as per protocol. Following completion of the subjective assessment, a basic explanation of the pelvic anatomy and physiology aided by diagrams, which is an aspect of behavioral therapy [7], was given to the patient.

Following the explanation, patient was told to attempt micturition initially with valsalva maneuver and crede maneuver as much as possible and then empty the remaining urine by intermittent catheterization and record the residual volume every time after the catheterization. Patient was advised to maintain a diary to record residual volumes. The importance of accurate recording was explained to the patient.

\section{Management and outcomes}

After the entire evaluations, physiotherapy treatment plan was framed which was consisted of - Electrical stimulation [8] and Pelvic floor exercises [9].

- 0-6 weeks

Surface electrical stimulation over inner thigh and suprapubic region continued for 3 months 
Effectiveness of Pelvic Floor Exercises Along with Faradic Stimulation on Bladder Retention and Quality of Life in Post-operative Case of Cauda Equina Syndrome. Case Report

- $\quad$ Current type- surge faradic current

- $\quad$ Frequency $-50-100 \mathrm{~Hz}$

- $\quad$ Pulse duration - $100 \mu \mathrm{s}$

- Intensity - maximum level tolerable

- Treatment time - 90 stimulations on each side for 6 days/ week for 4 months

Procedure for inner thigh

The patient was positioned in supine, with 30 degrees of hip abduction and knee flexion. One surface electrode of silicone $(2.0 \mathrm{~cm}$ $\times 3.0 \mathrm{~cm}$ ) and one pen electrode was used. Surface electrode was placed over the inner thigh and was fixed with masking tape. The pen electrode was placed over the superior aspect of inner thigh.

\section{Procedure for suprapubic region}

Patient was in crook lying position two surface electrodes were placed over the suprapubic region on either sides. And surge faradic current of similar parameters was used.

\section{Pelvic floor exercises}

Initially hold-relax and pelvic clock exercises were given in supine and then progressed in functional positions on balance foam cushion which consisted of:

- 0-6 weeks: One leg standing with contraction of vaginal muscles, one leg standing with contraction of rectal muscles, one leg standing and pelvic clock exercise

- 6-12 Weeks: Pelvic floor exercises were progressed on balance board- One leg standing with contraction of vaginal muscles, one leg standing with contraction of rectal muscles, one leg standing and pelvic clock exercise.

- 12-18 weeks: Pelvic floor exercises on balance board were progressed to- One leg squats with contraction of vaginal muscles on balance board- $5 \mathrm{~s}$ hold and 20 reps on each leg, one leg squats with contraction of rectal muscles, one leg standing on balance board with pelvic floor contraction and forced expiration to engage the abdominals.

This was accomplished gradually over 3 months. Patient was advised to perform these exercises at home.
Results

Quality of life

\begin{tabular}{|l|c|c|}
\hline $\begin{array}{l}\text { SF36 } \\
\text { questionnaire }\end{array}$ & $\begin{array}{c}\text { Pre Intervention } \\
\text { score }\end{array}$ & $\begin{array}{c}\text { Post Intervention } \\
\text { score }\end{array}$ \\
\hline & $36.11 \%$ & $84.77 \%$ \\
\hline
\end{tabular}

Table a

Residual volume and frequency of catheterization

\begin{tabular}{|l|c|}
\hline $\begin{array}{l}\text { Residual volume (after each episode } \\
\text { of catheterization) }\end{array}$ & Quantity \\
\hline January before treatment & $500-750 \mathrm{ml}$ \\
\hline January to February & $400-350 \mathrm{ml}$ \\
\hline In March & $100 \mathrm{ml}$ \\
\hline In June & $\mathrm{Nil}$ \\
\hline
\end{tabular}

Table b

Frequency of catheterization was reduced from 5 to 2 in the month of march and from the month of June patient was voiding urine voluntarily and was not using intermittent catheterization.

Bladder compliance and capacity

\begin{tabular}{|l|c|c|}
\hline & Pre intervention & Post intervention \\
\hline Bladder Compliance & $26.8 \mathrm{ml} / \mathrm{cm} \mathrm{H}_{2} \mathrm{O}$ & $89.7 \mathrm{ml} / \mathrm{cm} \mathrm{H}_{2} \mathrm{O}$ \\
\hline Bladder Capacity & $622 \mathrm{ml}$ & $444 \mathrm{ml}$ \\
\hline
\end{tabular}

Table c

\section{Perfect score}

\section{Discussion}

The present study was undertaken with the intention to see the effect of faradic stimulation along with pelvic floor exercise on urinary retention and quality of life. In this study the woman who underwent treatment with pelvic floor exercises and surface electrical stimulation presented a significant decrease in residual volume and reported an improvement in quality of life after the treatment for 3 months.

This can be explained as, electrodes placed over suprapubic region, pulsed (faradic) current functions as a stimulating factor that 
Effectiveness of Pelvic Floor Exercises Along with Faradic Stimulation on Bladder Retention and Quality of Life in Post-operative Case of Cauda Equina Syndrome. Case Report

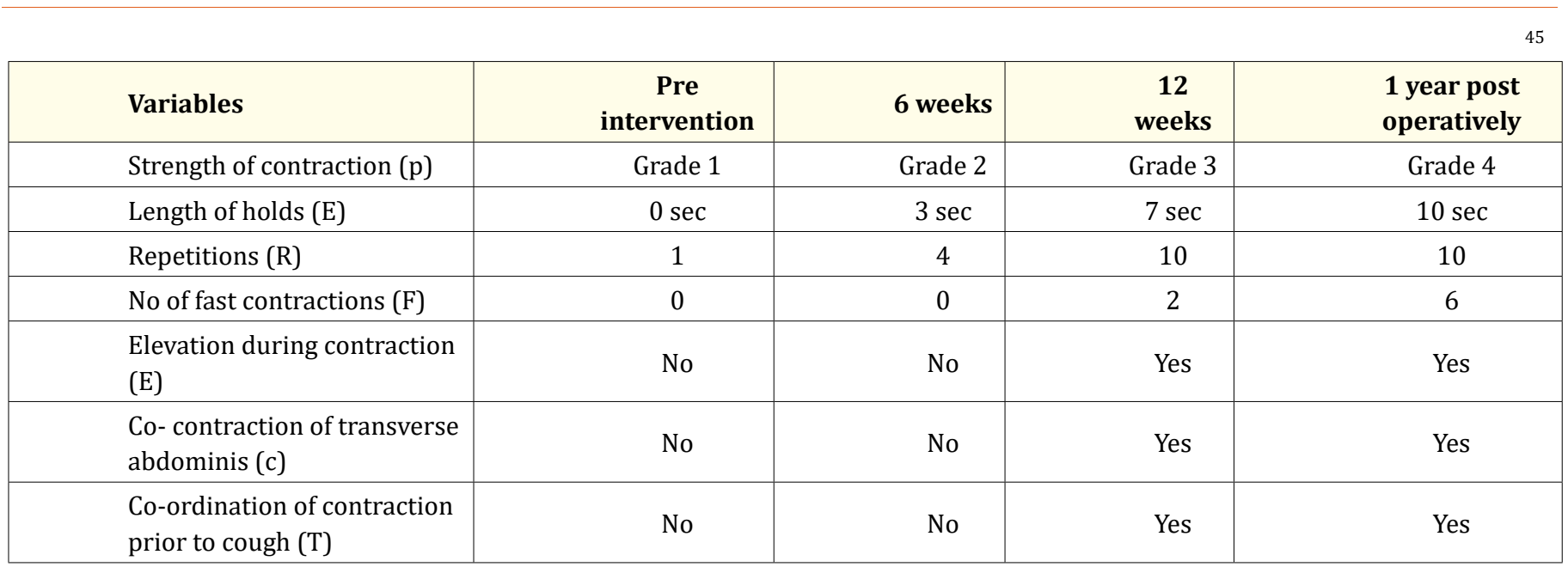

Table d

strengthens pelvic floor muscles. This makes the bladder muscles move and causing the contraction of the detrusor muscles and relaxation of the urethral sphincter hence urination occurs. Similar results were obtained in the study done by Huan li (2019) concluded that pelvic floor muscle strength was greatly increased after low frequency electrical stimulation in patients with urinary retention after cervical cancer operation [10]. Also stimulation over inner thigh muscles leads to contraction of hip adductors; this causes increased force generation in pelvic floor muscles as hip adductors are associated with pelvic floor muscles. The obturator internus muscle could perform the role of myofascial force transmission, as deep hip external rotator as hip adductor muscles have fascial attachment with pelvic floor muscles [11]. Low frequency electrical stimulation improved the blood circulation and elasticity of pelvic tissues (bladder and urethra). In addition, pulse current stimulation to the nerve controlling bladder (pudendal nerve) can also accelerate the recovery of nerves controlling the bladder and urethra [12].

In urine activity, the parasympathetic nerve plays a dominant role, while pelvic nerves originate from sacral spinal nerves (s2s4), which are rich of parasympathetic fibers, in which excitement due to electrical stimulation can make the detrusor contract and the internal bladder sphincter relax, promoting urination. Hence these are two possible explanations for the reduction in bladder retention with the use of electrical stimulation [13].
Position used in this study was described by Dumoulin., et al. (1995) who compared it with another positioning such as (sitting) and concluded that in this position current penetrates deeper within the pelvis [14]. Study by Kajbafzaden at also used this position of electrode in the children with myelomeningocele and found a good result [15].

In this study pelvic floor exercises in different functional positions were also given to the patient; which improved muscle strength and extensibility of pelvic floor muscles which were affected due to denervation. PFE improve muscle tone by strengthening the pubococcygeus muscle. Pelvic floor exercises demand maximum voluntary contraction hence the greatest number of muscle fibers are recruited and hence improvement in voluntary contraction and relaxation of urethral of sphincters is seen [9].

The general principles of muscle training program - overload and specificity (pelvic floor exercises in different functional positions) can be applied to pelvic floor muscles as well; because a study by Verelst., et al. suggested in both healthy and women with urinary incontinence the time-to fatigue ratio is about 10.5 to 11 seconds of hold with about $80 \%$ of maximal contraction values. This implies that it is necessary to overload the pelvic floor muscles for a training program to be effective but within the limits of fatigue [16].

According to Sapsford R (2004) pelvic floor muscles are not an isolated unit; coordination of pelvic floor muscles with thoraco/abdomino/pelvic muscles contribute to continence, antigravity sup- 
port, and intra-abdominal pressure [9]. Many studies have shown an increased understanding of the synergy between the abdominal and pelvic floor muscles. The pelvic floor muscles are now considered to have the dual function of providing trunk stability and contributing to continence. Hence exercises such as one leg standing on balance board/foam cushion/engaging abdominal muscles help in improving pelvic floor function and hence the continence [17].

The contribution of the pelvic floor muscles and trunk stability can be explained by its feedforward activation in response to trunk perturbation, resulting from rapid arm movement [18]. The pelvic floor muscles respond in a similar manner to the other components of the local muscle system including the transversus abdominis, the diaphragm and the deep fibers of multifidus (Moseley., et al. 2002). Hence exercises performed on balance board also led to activation of pelvic floor muscles.

\section{Conclusion}

Post-operative patients with cauda equine syndrome have shown improvement in urinary retention following a patient- specific physiotherapy treatment plan which included pelvic floor exercises and surface electrical stimulation.

\section{Conflict of Interest}

No potential conflict of interest relevant to this article was reported.

\section{Acknowledgments}

We would like to express our gratitude towards the members of organization for their kind co-operation and encouragement which helped us in completion of this research paper. Special gratitude and thanks to our guide for giving such attention and time.

\section{Bibliography}

1. Fraser S., et al. "Cauda equina syndrome: a literature review of its definition and clinical presentation". Archives of Physical Medicine and Rehabilitation 90.11 (2009): 1964-1968.

2. Gitelman A., et al. "Cauda equina syndrome: a comprehensive review". American Journal of Orthopedics (Belle Mead NJ) 37.11 (2008): 556-562.

3. Kapetanakis S., et al. "Cauda equina syndrome due to lumbar disc herniation: a review of literature". Folia Medica 59.4 (2017): 377-386.
4. Panicker JN., et al. "Lower urinary tract dysfunction in the neurological patient: clinical assessment and management". The Lancet Neurology 14.7 (2015): 720-732.

5. Delong WB., et al. "Timing of surgery in cauda equina syndrome with urinary retention: meta-analysis of observational studies". Journal of Neurosurgery: Spine 8.4 (2008): 305-320.

6. Laycock JO and Jerwood D. "Pelvic floor muscle assessment: the PERFECT scheme”. Physiotherapy 87.12 (2001): 631-642.

7. Rovner ES and Wein AJ. "Treatment options for stress urinary incontinence". Reviews in Urology 6 (2004): S29.

8. Correia GN., et al. "Effects of surface and intravaginal electrical stimulation in the treatment of women with stress urinary incontinence: randomized controlled trial". European Journal of Obstetrics and Gynecology and Reproductive Biology 173 (2014): 113-118.

9. Sapsford R. "Rehabilitation of pelvic floor muscles utilizing trunk stabilization”. Manual Therapy 9.1 (2004): 3-12.

10. Li H., et al. "Curative efficacy of low frequency electrical stimulation in preventing urinary retention after cervical cancer operation". World Journal of Surgical Oncology 17.1 (2019): 1-7.

11. Hwang UJ., et al. "Relationship Between Sexual Function and Pelvic Floor and Hip Muscle Strength in Women with Stress Urinary Incontinence”. Sexual Medicine 9.2 (2021): 100325.

12. McGee MJ., et al. "Electrical stimulation for the treatment of lower urinary tract dysfunction after spinal cord injury". The Journal of Spinal Cord Medicine 38.2 (2015): 135-146.

13. Prodanov D., et al. "Functional electric stimulation for sensory and motor functions: progress and problems". Biomedical Reviews 14 (2003): 23-50.

14. Dumoulin C., et al. "Determining the optimal pelvic floor muscle training regimen for women with stress urinary incontinence". Neurourology and Urodynamics 30.5 (2011): 746-753.

15. Kajbafzaden AM., et al. "Functional electrical stimulation for management of urinary incontinence in children with myelomeningocele: a randomized trial". Pediatric Surgery International 30 (2014): 663-668.

16. Vereslt $M$ and Leivseth G. "Force and stiffness of the pelvic floor as function of muscle length: A comparison between women with and without stress urinary incontinence". Neurourology and Urodynamics 26 (2007): 852-857. 
17. Sapsford RR., et al. "Co-activation of the abdominal and pelvic floor muscles during voluntary exercises". Neurourology and Urodynamics: Official Journal of the International Continence Society 20.1 (2001): 31-42.

18. Moseley A., et al. "Evidence for physiotherapy practice: a survery of the Physiotherapy Evidence Database (PEDro)". Australian Journal of Physiotherapy 48 (2002): 43-49.

\section{Assets from publication with us}

- Prompt Acknowledgement after receiving the article

- Thorough Double blinded peer review

- Rapid Publication

- Issue of Publication Certificate

- High visibility of your Published work

Website: www.actascientific.com/

Submit Article: www.actascientific.com/submission.php

Email us: editor@actascientific.com

Contact us: +919182824667 